\title{
Correction to: Implications of Applying "Clinically Significant Impairment" to Autism Assessment: Commentary on Six Problems Encountered in Clinical Practice
}

\author{
Rachel Jellett $^{1}$ (1) $\cdot$ Joshua Muggleton $^{2}$ (])
}

Published online: 12 May 2021

(c) Springer Science+Business Media, LLC, part of Springer Nature 2021

\section{Correction to: \\ Journal of Autism and Developmental Disorders \\ https://doi.org/10.1007/s10803-021-04988-9}

The original version of the article contained an error in copyright holder name. The correct copyright holder name and statement should be "The Author(s), under exclusive license to Springer Science+Business Media, LLC, part of Springer Nature".

The original article has been corrected.

Publisher's Note Springer Nature remains neutral with regard to jurisdictional claims in published maps and institutional affiliations.

The original article can be found online at https://doi.org/10.1007/ s10803-021-04988-9.

Joshua Muggleton

joshua.muggleton@nhs.scot

1 Olga Tennison Autism Research Centre, La Trobe University, Melbourne, VIC, Australia

2 Clinical Psychologist for NHS Fife, Lynebank Hospital, Halbeath Road, Dunfermline, Fife KY11 4UW, Scotland 